\title{
ANNOTATIONS
}

\section{A Portrait of Professor Priestley Smith}

On December 14, 1928, an interesting ceremony took place at the Queen's Hospital, Birmingham, when Mr. Priestley Smith, Emeritus Professor of Ophthalmology in the University of Birmingham, was presented with his portrait in appreciation of his connection with the hospital, which has lasted for more than half a century.

The portrait is by Mr. Harold Speed, and Mr. Priestley Smith, in replying to the presentation, asked that it might be hung in the Board Room of the hospital. It is a great and not a very common honour for a portrait of a member of the medical profession to be hung in a public institution during the lifetime of the original; we congratulate the hospital in thus receiving a portrait of one who all his life long has been an example to his city, worthy to be esteemed and held in honour and affection. And we congratulate Mr. Priestley Smith who, in addition to being Professor in Birmingham, has for many years been regarded as pre-eminent in the world of ophthalmology, and a master of clear cut thought and speech. : We know that the honour is well deserved and we know that it is one that will be a source of great gratification to him, to remember in the evening of his life the kindly feelings of his friends and the citizens of the great city of which he is a leading member. We feel sure that British ophthalmologists and, indeed, many others; will wish to possess a replica of what, we understand, is an excellent portrait, and it is to be hoped that an opportunity of doing so will be afforded them.

\section{Mescal}

Those of our readers who made a conscientious effort to study the details of the erudite Bowman Lecture of 1925 on the Psychology of Vision will be relieved to hear of a simpler method of investigation. Like many other labour-saving devices it comes from the other side of the Atlantic and takes the form of a drug known as mescal or peyotl. This particular poison is obtained from the Echinocactus Williamsii and is in common use among the Indians of Mexico and even of some of the southern of the United States. It already posesses quite a respectable bibliography of its own, and has recently formed the subject of one of the Psyche Miniatures. The author, Professor Klüver, Columbia University, gives a good account of the various experiments and their effects. Dr. Macdonald 
Critchley writes an introduction pointing out the possibilities of the drug in the study of the psychology of vision.

Apparently mescal is unique among drugs in that its main action is that of a stimulant of the visual and visuo-psychic areas of the cortex, producing visual hallucinations, alterations in the vividness of visual imagery, and apparent change in the aspect or behaviour of real objects. Those who wish to experiment with this strange drug should be warned that the resulting Katzenjammer on the following day seems to have been, in some of the subjects, very severe.

\section{ABSTRACTS}

\section{I.-NEUROLOGY}

(I) Dworjetz.-On the correctness of the designation "Atrophy of the optic nerve." (Ueber die Berechtigung der Bezeichnung "Atrophia nervi optici.") Klin. Monatsbl. f. Augenheilk., Bd. LXXX, S. 30, 1928.

(1) Dworjetz draws attention to a group of cases wherein the optic nerve may give a typical picture of advanced atrophy, with a white disc and small vessels, and yet, at the same time, the vision of the eye may remain tolerably good. He quotes nine cases. Of these the neurological diagnosis was:-One case, tabes; two, cerebro-spinal syphilis; one, disseminated sclerosis; one, disease of the antrum of the same side; two, post-typhoid ; two, alcohol poisoning. The ophthalmological diagnosis was :-Five cases of simple atrophy; three cases, neuritic atrophy; one case, atrophy after papilloedema. In each case the clinical appearances were those of total atrophy.

He concludes that a completely white nerve head does not exclude the presence of visual acuity; that optic atrophy cannot be diagnosed on the clinical appearance of the nerve head; that an atrophic appearance does not necessarily indicate an atrophy of the nerve fibres; and that the intensity of whiteness of the disc is no guide to the degree of actual atrophy which is present. He suggests that cases, which show an atrophic appearance with retention of vision, should not be called cases of optic atrophy at all, but that the term Hypotrophy or atrophy in the nerve, not of it, should be used.

W. S. Duke-Elder. 